\title{
HUBUNGAN DUKUNGAN SOSIAL KELUARGA DAN PENGETAHUAN \\ DENGAN PERILAKU PENGENDALIAN HIPERTENSI DI WILAYAH \\ KERJA PUSKESMAS KARANGNUNGGAL KABUPATEN \\ TASIKMALAYA
}

\author{
RELATIONSHIP OF FAMILY SOCIAL SUPPORTAND KNOWLEDGE \\ WITHHYPERTENSION CONTROL BEHAVIOR IN \\ KARANGNUNGGAL WORKING PUSKESMAS \\ AREA TASIKMALAYA REGENCY
}

\author{
Dian Saraswati ${ }^{1}$, Asep Suryana Abdurrahmat ${ }^{2}$, Siti Novianti ${ }^{3}$ \\ Program Studi Kesehatan Masyarakat Fakultas Ilmu Kesehatan Universitas Siliwangi \\ Alamat Kampus : Jalan Siliwangi Nomor 24 Tasikmalaya 46115 \\ diansaraswati@unsil.ac.id,
}

\begin{abstract}
ABSTRAK
Hipertensi merupakan penyakit kornis yang secara independen berhubungan dengan penyakit kardiovaskuler.Hipertensi ini merupakan faktor risiko terbanyak penyakit serebrovaskuler seperti stroke.Penelitian ini bertujuan untuk membuat model determinan pengetahuan dan dukungan sosial keluarga dengan perilaku pengendalian hipertensi di Puskesmas Karangnunggal Kabupaten Tasikmalaya.Penelitian ini menggunakan desain kross seksional dengan jumlah sampel sebanyak 188 orang yang diambil secara purposif. Analisis bivariat dengan menggunakan uji statistik kai square pada derajat kepercayaan $95 \%$. Hasil analisis sebanyak $70,4 \%$ responden memiliki dukungan sosial keluarga baik, sebanyak 38,3\% memiliki pengetahuan baik, 36,2\% memiliki kepatuhan minum obat kurang baik dan 16,5\% memiliki perilaku pengendalian hipertensi kurang baik. Hasil analisis bivariat diperoleh nilai signifikan bahwa variabel dukungan sosial keluarga dan pengetahuan berhubungan dengan perilaku pengendalian hipertensi dengan masing-masing nilai p 0,013 dan 0,03.
\end{abstract}

Kata kunci :Dukungan sosial keluarga, Pengetahuan, Pengendalian hipertensi

ABSTRACT

Hypertension is a coronary disease that is independently associated with cardiovascular disease. This hypertension is the most risk factor for cerebrovascular diseases such as stroke. This study aims to make a determinant model of knowledge and social support of families with hypertension control behavior in Puskesmas Karangnunggal, Tasikmalaya Regency. This study uses a cross sectional design with a sample of 188 people taken purposively. Bivariate analysis using kai square statistical test at 95\% confidence level. The results of analysis were $70.4 \%$ of respondents had good family social support, as many as 38.3\% had good knowledge, $36.2 \%$ had poor medication adherence and $16.5 \%$ had poor hypertension control behavior. The results of the bivariate analysis obtained a significant value that the variables of family social support and knowledge were related to hypertension control behavior with each p value of 0.013 and 0.03. Hypertension patients need to be remainded to obey taking medication as part of hypertension control behavior.

Kata kunci :hypertension control behavior, family social support, knowledge 


\section{PENDAHULUAN}

Hipertensi merupakan penyakit kornis yang secara independen berhubungan dengan penyakit kardiovaskuler pada kelompok lansia. Hipertensi ini merupakan faktor risiko terbanyak penyakit serebrovaskuler seperti stroke. ${ }^{1}$ Hipertensi juga merupakan masalah kesehatan masyarakat terbanyak di sebagian besar negara-negara dunia. Hampir semua konsensus/ pedoman utama baik dari dalam walaupun luar negeri, menyatakan bahwa seseorang akan dikatakan hipertensi bila memiliki tekanan darah sistolik $\geq 140 \mathrm{mmHg}$ dan atau tekanan darah diastolik $\geq 90 \mathrm{mmHg}$, pada pemeriksaan yang berulang. ${ }^{2}$

Berdasarkan data WHO tahun 2013 menunjukan bahwa hipertensi diderita oleh 1 miliar orang di seluruh dunia. Diperkirakan tahun 2025 meningkat menjadi 1,5 miliar orang. Di Indonesia angka hipertensi mencapai 25,8\% dari seluruh penduduk Indonesia. Menurut Riskesdas Nasional tahun 2013 hipertensi berada di urutan ketiga penyebab kematian semua umur, setelah stroke dan TB, dengan proporsi kematian sebesar 6,8\% (Riskesdas : 2013). ${ }^{3}$

Hasil riset yang dilakukan oleh Pusat Data dan Informasi (PUSDATIN) kementrian Kesehatan Republik Indonesia tahun 2015 menunjukan bahwa Provinsi Jawa Barat berada di posisi ke tiga (3) dari total 33 Provinsi yang ada di Indonesia setelah Kalimantan Selatan di posisi pertama (1) dan Sulawesi Utara di posisi ke dua (2). Kalimantan Selatan 40,7\% masyarakatnya hipertensi dan terdapat $27,7 \%$ masyarakat kurang menyadari bahwa dirinya mengidap hipertensi. Sulawesi Utara 40,3\% masyarakatnya hipertensi dan terdapat 25,3\% masyarakat kurang menyadari bahwa dirinya mengidap hipertensi. Jawa Barat 30,9\% masyarakatnya hipertensi dan terdapat 20,9\% masyarakat Provinsi Jawa Barat yang kurang menyadari bahwa dirinya mengidap hipertensi (PUSDATIN : 2015). ${ }^{4}$

Menurut Muhammadun (2010) dalam Dalyoko, dkk, (2011) ada beberapa hal yang dapat dilakukan dalam upaya pengendalian hipertensi yaitu dengan cara farmakologi dan non-farmakologi. Terapi secara farmakologi yaitu dengan patuh mengkonsumsi obatobatan antihipertensi. ${ }^{5}$

Tatalaksana nonfarmakologis seperti menurunkan berat badan bagi pasien yang obesitas, olahraga, berhenti mengonsumsi alkohol, dan berhenti merokok, terbukti dapat menurunkan tekanan darah. Sedangkan secara non-farmakologi diantaranya dengan olahraga teratur, istirahat yang cukup, mengurangi minum alkohol, cara tradisional seperti pijat hipertensi, mengatur pola makan, mengurangi konsumsi garam sekitar 3 gram perhari atau dalam ukuran rumah tangga adalah sekitar satu sendok teh perhari. ${ }^{2,6}$

Menjalani pola hidup sehat telah banyak terbukti dapat menurunkan tekanan darah, dan secara umum sangat menguntungkan dalam menurunkan risiko permasalahan kardiovaskular.Pada pasien yang menderita hipertensi derajat 1, tanpa faktor risiko kardiovaskular lain, maka strategi pola hidup sehat merupakan tatalaksana tahap awal, yang harus dijalani setidaknya selama $4-6$ bulan.Bila setelah jangka waktu tersebut, tidak 
didapatkan penurunan tekanan darah yang diharapkan atau didapatkan faktor risiko kardiovaskular yang lain, maka sangat dianjurkan untuk memulai terapi farmakologi (PERKI, 2015). ${ }^{2}$

Laju kontrol tekanan darah pasien hipertensi yang tidak obesitas lebih cepat dibandingkan dengan yang obesitas dan pasien yang tidak merokok memiliki kecenderungan untuk terkontrol 8.1 kali lebih besar dibandingkan dengan yang merokok. ${ }^{7}$ Telah banyak upaya dan tindakan yang dilakukan untuk mengatasi hipertensi antara lain kerjasama pemerintah dengan Indonesian Society of Hypertension (InaSH) dan pembentukan Direktoral Pengendalian Penyakit Tidak Menular. ${ }^{8}$ Namun tatalaksana hipertensi masih belum berhasil. Menurut Badan Kesehatan Dunia (WHO), dari $50 \%$ pasien hipertensi yang terdeteksi, hanya $25 \%$ yang mendapat pengobatan dan hanya $12,5 \%$ bisa diobati dengan baik.

Menurut Suhardjono (2008) dalam Hairunisa (2014), dampak dari ketidakpatuhan mengontrol atau pengendalian hipertensi dapat menyebabkan komplikasi seperti kerusakan organ meliputi otak, karena hipertensi yang tidak terkontrol dapat meningkatkan risiko stroke kemudian kerusakan pada jantung, hipertensi meningkatkan beban kerja jantung yang akan menyebabkan pembesaran jantung sehingga meneningkatkan risiko gagal jantung, dan gagal ginjal. ${ }^{9}$ Kemenkes RI meluncurkan program Germas (Gerakan Masyarakat) termasuk untuk pengendalian hipertensi melalui kegiatan CERDIK yang merupakan singkatan dari cek tekanan darah rutin, berhenti merokok, rutin aktifitas fisik, diet seimbang, istirahat cukup dan kurangi stress. Manajemen pengelolaan hipertensi dipengaruhi oleh faktor-faktor seperti faktor pengetahuan, sikap, dukungan keluarga, faktor fisiologis dan psikologis, kepatuhan minum obat. ${ }^{10}$ Hasil penelitian Dalyoko menunjukkan ada hubungan antara pengetahuan dengan upaya pengendalian hipertensi.Pengetahuan berperan penting dalam membentuk perilaku atau tindakan seseorang. Pengetahuan dapat diperoleh baik dari diri pasien sendiri berdasarkan pengalaman hidup sehari-hari dan dari orang lain. ${ }^{5}$

Berdasarkan penelitian Herlinah dkk, 2013 menunjukan bahwa dukungan sosial keluarga merupakan faktor yang penting terhadap perilaku lansia dalam pengendalianhipertensi.Hal ini sesuai juga dengan penelitian Suardana dkk, 2014 yang juga menyatakan terdapat hubungan antara dukungan keluarga dengan kualitas hidup lansia yang mengalami hipertensi.

Data yang diperoleh dari Dinas Kesehatan Kabupaten Tasikmalaya tahun 2016, tercatat bahwa jumlah penduduk yang ada di lingkungan kabupaten Tasikmalaya adalah sebanyak 1.735 .998 orang. Dari jumlah tersebut, terdapat 12.186 penduduk atau sekitar $\quad 0,70 \%$ penduduk Kabupaten Tasikmalaya yang terkena penyakit hipertensi (Laporan Dinas Kesehatan kab. Tasikmalaya, 2016).Adapun data yang diperoleh dari Puskesmas Karangnunggal pada tahun 2017, terdapat 111 angka kesakitan hipertensi lansia yang berobat jalan ke puskesmas Karangnunggal.Berdasarkan dari gambaran di 
atas penulis tertarik untuk melakukan penelitian dengan judul "hubunganpengetahuan dan dukungan sosial keluarga dengan perilaku pengendalian hipertensi di wilayah Kerja Puskesmas Karangnunggal tahun 2017”.

\section{METODE}

Variabel bebas dalam penelitian ini adalah determinan dalam pengendalian hipertensi yaitu faktor dukungan sosial keluarga dan pengetahuan.Variabel dukungan sosial keluarga meliputi dukungan emosional, dukungan instrumental, dukungan informasional dan dukungan penghargaan. Variabel terikatnya adalah praktek pengendalian hipertensi yang meliputi aspek farmakologis yaitu kepatuhan minum obat dan aspek non farmakologis yang meliputi cek tekanan darah rutin, berhenti merokok, rutin aktifitas fisik,diet seimbang,istirahat yang cukup dan manajemen stress.

Penelitian ini termasuk ke dalam jenis penelitian observasional analitik dengan menggunakan desain penelitian cross sectional. Populasi penelitian dilakukan pada pasien peserta Prolanis yang didiagnosis Hipertensi dan berobat minimal 3 bulan berturut-turut

di

Puskesmas

Karangnunggal.Jumlah sampel sebanyak 188

orang diperoleh dari rata-rata pasien hipertensi yang berobat selama satu tahun terakhir (tahun

2017) dengan teknik pengambilan purposif.Kriteria eksklusi sampel adalah penderita hipertensi yang mengalami komplikasi dan tidak mampu berkomunikasi. Pengumpulan data dilakukan melalui wawancara dengan menggunakan kuesioner.

Data yang terkumpul selanjutnya akandianalisis secara statistikadengan menggunakan analisis bivariatdengan menggunakan uji statistik chi square pada derajat kepercayaan $95 \%$.

\section{HASIL PENELITIAN DAN PEMBAHASAN}

\section{A. Gambaran Karakteristik Responden}

Sebagian besar responden berjenis kelamin wanita $(69,7 \%)$, dengan usia ratarata 61,4 tahun. Tingkat pendidikan sebagian besar tamat SD $(53,2 \%)$ dan sebanyak $41 \%$ memiliki pekerjaan sebagai ibu rumah tangga.

B. Hasil Deskripsi Data Penelitian

1. Dukungan Sosial Keluarga 


\begin{tabular}{|c|c|c|c|c|c|}
\hline No & Dukungan Emosional & $\begin{array}{c}\text { Tidak } \\
\text { pernah }\end{array}$ & Jarang & Sering & Selalu \\
\hline 1 & $\begin{array}{l}\text { Keluarga selalu memberi } \\
\text { dorongan kepada saya untuk } \\
\text { tetap menjaga kesehatan } \\
\text { dirinya. }\end{array}$ & $\begin{array}{c}2 \\
(1,1)\end{array}$ & $\begin{array}{c}2 \\
(1,1)\end{array}$ & $\begin{array}{c}J \\
(2,7)\end{array}$ & $179(95,2)$ \\
\hline 2 & $\begin{array}{l}\text { Keluarga menganjurkan } \\
\text { kepada saya untuk selalu } \\
\text { melaksanakan terapi (diet, } \\
\text { berobat, olahraga) sesuai } \\
\text { anjuran }\end{array}$ & $(1,1)$ & $(1,1)$ & $23(12,2)$ & $161(85,6)$ \\
\hline 2 & $\begin{array}{l}\text { Keluarga menasehati jika saya } \\
\text { susah melaksanakan terapi } \\
\text { (diet, berobat, olahraga) sesuai } \\
\text { anjuran. }\end{array}$ & $\begin{array}{c}2 \\
(1,1)\end{array}$ & $\begin{array}{c}< \\
(1,1)\end{array}$ & $39(20,7)$ & $145(77,1)$ \\
\hline$\Delta$ & $\begin{array}{l}\text { Keluarga membiarkan saya } \\
\text { makan dan minum apa saja } \\
\text { yang disukai walaupun itu } \\
\text { tidak sesuai anjuran }\end{array}$ & $\begin{array}{c}2 \\
(1,1)\end{array}$ & $\begin{array}{c}J \\
(1,6)\end{array}$ & $29(15,4)$ & $154(81,9)$ \\
\hline
\end{tabular}

\section{Tabel 1. Dukungan Emosional Keluarga Responden di Wilayah Kerja Puskesmas Karangnunggal Tahun 2018}

Sumber : Data Primer, 2018

Hasil wawancara dengan responden mengenai dukungan emosional, sebanyak 95,2\%memberikan dukungan berupadorongandari keluarga untukselalukesehatan dirinya, dan $77,1 \%$ keluarga selalu menasehati responden jika sulit untuk melaksanakan terapi.

Tabel 2. Dukungan Penghargaan Keluarga Responden di Wilayah Kerja Puskesmas Karangnunggal Tahun 2018

\begin{tabular}{|c|c|c|c|c|c|}
\hline No & Dukungan Penghargaan & $\begin{array}{l}\text { Tidak } \\
\text { pernah }\end{array}$ & Jarang & Sering & Selalu \\
\hline 1 & $\begin{array}{l}\text { Keluarga memberi pujian } \\
\text { atas usaha yang saya } \\
\text { lakukan untuk } \\
\text { melaksanakan terapi (diet, } \\
\text { berobat, olahraga) sesuai } \\
\text { anjuran dokter. }\end{array}$ & $\begin{array}{c}2 \\
(1,1)\end{array}$ & $\begin{array}{c}1 \\
(0,5)\end{array}$ & $36(19,1)$ & $149(79,3)$ \\
\hline & $\begin{array}{l}\text { Keluarga tidak marah } \\
\text { ketika saya tidak mau } \\
\text { mentaati aturan terapi (diet, } \\
\text { berobat, olahraga) yang } \\
\text { telah ditetapkan. }\end{array}$ & $\begin{array}{c}2 \\
(1,1)\end{array}$ & 0 & $44(23,4)$ & $142(75,5)$ \\
\hline 3 & $\begin{array}{l}\text { Keluarga tidak mengawasi } \\
\text { pelaksanaan aturan terapi } \\
\text { (diet, berobat, olahraga) }\end{array}$ & $\begin{array}{c}2 \\
(1,1)\end{array}$ & $2(1,1)$ & $35(18,6)$ & $149(79,3)$ \\
\hline
\end{tabular}


ang sedang saya jalani.

Sumbe

$\begin{array}{lllllll}\text { Keluarga } & \text { sulit } & \text { menerima } & 162 & 0 & 24(12,8) & 2(1,1)\end{array}$

4 saya apa adanya dengan (86,2)

Data

segala keterbatasan.

Prime

$r, 2018$

Sebanyak 79,3\% responden menyatakan

sebanyak 86,2\% keluarga responden tidak bahwa keluarga tidak selalu mengawasi pernah kesulitan untuk menerima apa adanya pelaksanaan aturan terapi seperti dalam diet dengan segala keterbatasan. pengobatan, olahraga yang pasien jalani, dan

Tabel 3. Dukungan Informasional Keluarga Responden di Wilayah Kerja Puskesmas Karangnunggal Tahun 2018

\begin{tabular}{clcccc}
\hline No & \multicolumn{1}{c}{ Dukungan Informasional } & $\begin{array}{c}\text { Tidak } \\
\text { pernah }\end{array}$ & Jarang & Sering & Selalu \\
\hline 1 & $\begin{array}{l}\text { Keluarga tidak pernah } \\
\text { mengingatkan saya untuk selalu } \\
\text { mematuhi aturan terapi ( diet, } \\
\text { berobat, olahraga) yang sedang } \\
\text { dijalani. }\end{array}$ & & $3(1,6)$ & 23 & $160(85,1)$ \\
\hline 2 & $\begin{array}{l}\text { Keluarga memberitahu makanan } \\
\text { apa saja yang harus dihindari }\end{array}$ & $2(1,1)$ & $1(0,5)$ & 48 & $137(72,9)$ \\
\hline 3 & $\begin{array}{l}\text { Keluarga memberitahu semua } \\
\text { informasi tentang tujuan dan } \\
\text { manfaat dari aturan terapi (diet, } \\
\text { berobat, olahraga) yang sedang } \\
\text { dijalani }\end{array}$ & & $1(0,5)$ & $24,5)$ & $161(85,6)$ \\
\end{tabular}

Sumber : Data Primer, 2018

Sebanyak $72,9 \%$ responden selalu bentuk pemberitahuan mengenai makanan menerima dukungan informasional dalam apa saja yang perlu dihindari.

Tabel 4. Dukungan Instrumental Keluarga Responden Karangnunggal di Wilayah Kerja Puskesmas Tahun 2018

\begin{tabular}{|c|c|c|c|c|c|}
\hline No & Dukungan Instrumental & $\begin{array}{r}\text { Tidak } \\
\text { pernah }\end{array}$ & Jarang & Sering & Selalu \\
\hline 1 & $\begin{array}{l}\text { Keluarga mengantar atau } \\
\text { mendampingi saya untuk } \\
\text { berobat kepelavanan kesehatan }\end{array}$ & $\begin{array}{c}3 \\
(1,6)\end{array}$ & $\begin{array}{c}1 \\
(0,5)\end{array}$ & $18(9,6)$ & $166(88,3)$ \\
\hline
\end{tabular}

\begin{tabular}{|c|c|c|c|c|c|}
\hline 2 & $\begin{array}{l}\text { Keluarga keberatan membiayai } \\
\text { pengobatan saya }\end{array}$ & $\begin{array}{c}4 \\
(2,1)\end{array}$ & $\begin{array}{c}1 \\
(0,5)\end{array}$ & $15(8,0)$ & $168(89,4)$ \\
\hline 3 & $\begin{array}{l}\text { Keluarga tidak pernah } \\
\text { meluangkan waktu untuk } \\
\text { mendengarkan cerita ataupun } \\
\text { keluhan-keluhan yang ingin } \\
\text { saya sampaikan }\end{array}$ & $\begin{array}{c}2 \\
(1,1)\end{array}$ & $\begin{array}{c}3 \\
(1,6)\end{array}$ & $12(6,4)$ & $171(91,0)$ \\
\hline
\end{tabular}

Sumber : Data Primer, 2018 
Sesuai tabel di atas, sebanyak 88,3\% responden selalu mendapatkan dukungan instrumental berupa pendampingan setiap kali berobat ke pelayanan kesehatan, dan 85,6\% responden menyatakan bahwa keluarga selalu memberitahukan semua informasi tentang tujuan dan manfaat dari aturan terapi yang sedang dijalani.
Selanjutnya seluruh komponen dukungan sosial keluarga dilakukan skoring untuk masing-masing jawaban yang telah diberikan responden dan dilakukan pengkategorisasian menjadi dua kategori yaitu kategori kurang baik dan baik, dengan kriteria kurang baik jika skor kurang dari 12 dan kategori baik jika skor 12 atau lebih. Adapun hasil kategori sebagaimana tabel berikut :

Tabel 5. Kategori Dukungan Sosial Keluarga Respondendi Wilayah Kerja Puskesmas Karangnunggal Tahun 2018

\begin{tabular}{|c|c|c|}
\hline Dukungan Sosial Keluarga & $\mathrm{f}$ & $\%$ \\
\hline a. Kurang Baik & 48 & 25,6 \\
\hline b. Baik & 140 & 70,4 \\
\hline Total & 188 & 100,0 \\
\hline
\end{tabular}

Sumber : Data Primer, 2018

Berdasarkan kategori dukungan sosial keluarga, sebanyak $70,4 \%$ responden berada pada kategori dukungan sosial keluarga baik dan 25,6\% responden memiliki dukungan sosial keluarga pada kategori baik.

2. Pengetahuan tentangPengendalian Hipertensi Responden

Tabel 6. Pengetahuantentang Pengendalian Hipertensi Respondendi Wilayah Kerja Puskesmas Karangnunggal Tahun 2018

\begin{tabular}{clccc}
\hline No & \multicolumn{1}{c}{ Variabel } & Ya & Tidak & Tidak Tahu \\
\hline 1 & $\begin{array}{l}\text { Tekanan darah 140 mmHg } \\
\text { sudah termasuk ke dalam }\end{array}$ & $\begin{array}{c}71 \\
(37,8)\end{array}$ & $\begin{array}{c}103 \\
(54,8)\end{array}$ & $\begin{array}{c}14 \\
\text { kategori hipertensi derajat }\end{array}$ \\
2 & $\begin{array}{l}\text { Cek tekanan darah secara } \\
\text { teratur merupakan bentuk } \\
\text { pengendalian hipertensi } \\
\text { Minum obat hipertensi hanya }\end{array}$ & $68(36,2)$ & $120(63,8)$ & $0(0)$ \\
jika tekanan darah sedang & $167(88,8)$ & & $1(0,5)$ \\
4 & $\begin{array}{l}\text { Membatasi konsumsi garam } \\
\text { tidak perlu dilakukan jika sudah } \\
\text { mengkonsumsi obat hipertensi }\end{array}$ & $107(56,9)$ & $107(56,9)$ & $0(0)$ \\
5 & $\begin{array}{l}\text { Berhenti merokok bisa } \\
\text { menurunkan tekanan darah }\end{array}$ & $70(37,2)$ & $70(37,2)$ & $0(0)$ \\
6 & $\begin{array}{l}\text { Penderita hipertensi perlu } \\
\text { mengontrol berat badan }\end{array}$ & $69(36,7)$ & $69(36,7)$ & $1(0,5)$ \\
Berjalan secara rutin bisa & $69(36,7)$ & $69(36,7)$ & $0(0)$
\end{tabular}




\begin{tabular}{cllll}
\hline \multicolumn{6}{l}{ menurunkan tekanan darah } & & \\
8 & $\begin{array}{l}\text { Meditasi dan yoga merupakan } \\
\text { metode relaksasi untuk } \\
\text { menurunkan tekanan darah }\end{array}$ & $67(35,6)$ & $67(35,6)$ & $45(23,9)$ \\
9 & $\begin{array}{l}\text { Memperbanyak konsumsi sayur } \\
\text { dan buah bisa menurunkan } \\
\text { tekanan darah } \\
\text { Minum alkohol dapat } \\
\text { meningkatkan tekanan darah }\end{array}$ & $70(37,2)$ & $69(36,7)$ & $0(0)$ \\
\end{tabular}

Sumber : Data Primer, 2018

Hasil pengetahuan mengenai bahwa obat hipertensi tidak perlu diminum manajemen hipertensi pada responden, kalau tekanan darah sudah turun dan 56,9 sebanyak 54,8\% menyatakan bahwa \% mengetahui bahwa diet rendah garam tekanan darah 140/90 mmHg tidak perlu dilakukan meskipun sudah minum termasuk hipertensi, $88,8 \%$ menyebutkan obat anti hipertensi.

Tabel 7. Kategori Pengetahuan tentang Pengendalian Hipertensi pada Responden di Wilayah Kerja Puskesmas Karangnunggal Tahun 2018

\begin{tabular}{|c|c|c|}
\hline Pengetahuan & f & $\%$ \\
\hline a. Kurang Baik & 116 & 61,7 \\
\hline b. Baik & 72 & 38,3 \\
\hline Total & 188 & 100,0 \\
\hline
\end{tabular}

Sumber : Data Primer, 2018

Sesuai dengan hasil tabel di atas, pengetahuan tentang manajeman hipertensi sebanyak $61,7 \%$ responden memiliki pada kategori kurang baik.

3. Perilaku Kepatuhan Minum Obat Hipertensi

Tabel 8. Perilaku Kepatuhan Minum Obat Hipertensi Responden Karangnunggal di Wilayah Kerja Puskesmas Tahun 2018

\begin{tabular}{|c|c|c|c|}
\hline \multirow{2}{*}{ No } & \multirow{2}{*}{ Pertanyaan } & \multicolumn{2}{|c|}{ Ya } \\
\hline & & f & $\%$ \\
\hline 1. & Pernahkah Anda lupa minum obat & 111 & 59,0 \\
\hline 2. & $\begin{array}{l}\text { Selain lupa, pernahkah Anda tidak minum obat karena alasan yang } \\
\text { lain dalam } 2 \text { minggu terakhir? }\end{array}$ & 105 & 55,9 \\
\hline 3. & $\begin{array}{l}\text { Pernahkah Anda mengurangi atau berhenti minum obat tanpa } \\
\text { sepengetahuan Dokter/Petugas Kesehatan karena Anda merasa } \\
\text { bahwa obat yang diberikan membuat keadaan Anda menjadi lebih } \\
\text { buruk }\end{array}$ & 120 & 63,9 \\
\hline 4. & Pernahkan Anda lupa membawa obat saat bepergian & 117 & 62,2 \\
\hline 5. & Apakah Anda tidak minum obat Anda kemarin? & 117 & 62,2 \\
\hline 6. & Apakah Anda berhenti minum obat ketika Anda merasa gejala yang & 118 & 62,8 \\
\hline
\end{tabular}


dialami telah teratasi ?

Meminum obat setiap hari merupakan suatu ketidaknyamanan untuk

7. beberapa orang. Apakah Anda merasa terganggu untuk minum obat

setiap hari ?

Seberapa sering Anda lupa minum obat?

a. Tidak pernah (tidak pernah lupa)

b. Sesekali (sekali seminggu)

8. c. Kadang-kadang (2-3 kali dalam seminggu)

11259,6

d. Biasanya (4-6 kali dalam seminggu)

e. Selalu (7 kali dalam seminggu)

Sumber : Data Primer, 2018

Hasil kuesioner mengenai kepatuhan

berhenti minum obat tanpa sepengetahuan

minum obat, $59 \%$ responden pernah lupa

dokter/petugas kesehatan; dan 63,9\% tidak

minum obat; $63,9 \%$ responden pernah

nyaman untuk minum obat setiap hari.

Tabel 9. Kategori Kepatuhan Minum Obat pada Responden di Wilayah Kerja Puskesmas Karangnunggal Tahun 2018

Kepatuhan Minum Obat

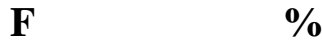

a. Kurang Baik

120

63,8

b. Baik

68

36,2

Sumber : Data Primer, 2018

Sebanyak $63,8 \%$ responden memiliki

kepatuhan minum obat antihipertensi pada

kategori kurang baik.

4. Perilaku Pengendalian Hipertensi

Tabel 10. Perilaku Manajemen Hipertensi Responden di Wilayah Kerja Puskesmas Karangnunggal Tahun 2018

\begin{tabular}{clcc}
\hline No & \multicolumn{1}{c}{ Variabel } & f & \% \\
\hline 1 & $\begin{array}{l}\text { Kepatuhan minum obat hipertensi } \\
\text { Saya memperbanyak asupan sayur dan buah setiap } \\
\text { harinya } \\
\text { Saya membatasi asupan dari makanan kaleng, } \\
\text { makanan cepat saji dan makanan olahan setiap } \\
\text { harinya }\end{array}$ & 68 & 36,2 \\
4 & $\begin{array}{l}\text { Saya membatasi asupan garam tidak lebih dari 2 } \\
\text { gr/hari }\end{array}$ & 9 & 197,1 \\
5 & $\begin{array}{l}\text { Saya melakukan olahraga teratur 30-60 menit per hari } \\
\text { dan 3 kali seminggu }\end{array}$ & 178 \\
6 & $\begin{array}{l}\text { Saya terbiasa berjalan kaki/ mengendarai sepeda atau } \\
\text { menaiki tangga dalam aktifitas rutin sehari-hari }\end{array}$ & 189,2 \\
\hline
\end{tabular}




\begin{tabular}{|c|c|c|c|}
\hline 7 & $\begin{array}{l}\text { Saya tidak menkonsumsi alcohol dan membatasi } \\
\text { konsumsi maksimal } 2 \text { gelas per hari }\end{array}$ & 165 & 87,8 \\
\hline 8 & Saya sudah berhenti merokok & 23 & 12,2 \\
\hline 9 & $\begin{array}{l}\text { Saya memiliki waktu tidur dan istirahat yang cukup } \\
\text { setiap hari }\end{array}$ & 41 & 21,8 \\
\hline 10 & Saya berupaya untuk mengendalikan stress & 20 & 10,6 \\
\hline 11 & $\begin{array}{l}\text { Saya rutin mengecek tekanan darah minimal satu } \\
\text { bulan sekali }\end{array}$ & 188 & 100,0 \\
\hline
\end{tabular}

Sumber : Data Primer, 2018

Berdasarkan kuesioner mengenai asupan makanan kaleng dan cepat saji, perilaku manajemen hipertensi, 36,2\% hanya $4,8 \%$ yang membatasi asupan garam responden tidak patuh minum obat. Hanya $19,1 \%$ yang memperbanyak asupan sayur dan hanya $12,2 \%$ yang sudah berhenti merokok.

dan buah setiap hari, 99,5\% membatasi

Tabel 11. Kategori Perilaku Pengendalian Hipertensi pada Respondendi Wilayah Kerja Puskesmas Karangnunggal Tahun 2018

\begin{tabular}{|c|c|c|}
\hline Perilaku Pengendalian Hipertensi & f & $\%$ \\
\hline a. Kurang Baik & 31 & 16,5 \\
\hline b. Baik & 157 & 83,5 \\
\hline Total & 188 & 100,0 \\
\hline
\end{tabular}

Sumber : Data Primer, 2018

Sebanyak $83,5 \%$ responden memiliki

hipertensi kurang baik.

perilaku pengendalian.

C. Hasil Analisis Bivariat dan Pembahasan

1. Hubungan Dukungan Sosial Keluarga dengan Perilaku Pengendalian Hipertensi

Tabel 12. Analisis Bivariat Hubungan Dukungan Sosial Keluarga dengan Perilaku Pengendalian Hipertensi di Wilayah Kerja Puskesmas Karangnunggal Tasikmalaya Tahun 2018

\begin{tabular}{|c|c|c|c|c|}
\hline \multirow{3}{*}{$\begin{array}{c}\text { Dukungan Sosial } \\
\text { Keluarga }\end{array}$} & \multicolumn{2}{|c|}{ Pengendalian Hipertensi } & \multirow[b]{2}{*}{ Jumlah } & \multirow{3}{*}{$\begin{array}{c}\text { Nilai } \\
p\end{array}$} \\
\hline & $\begin{array}{c}\text { Kurang } \\
\text { Baik }\end{array}$ & Baik & & \\
\hline & $\begin{array}{c}\mathbf{f} \\
\%\end{array}$ & $\begin{array}{l}\mathrm{f} \\
\%\end{array}$ & $\begin{array}{l}\mathrm{f} \\
\%\end{array}$ & \\
\hline Kurang Baik & 14 & 34 & 48 & \\
\hline & 29,2 & 70,8 & 100,0 & $\cap \cap 1 \cap$ \\
\hline Baik & 17 & 123 & 140 & ' \\
\hline & 12,1 & 87,9 & 100,0 & \\
\hline
\end{tabular}

Sumber : Data Primer, 2018 
Proporsi pengendalian hipertensi yang kurang baik lebih banyak ditemukan pada responden yang memiliki dukungan sosial kurang baik dibandingkan dengan pengendalian hipertensi yang baik. Hasil analisis bivariat diperoleh nilai $p 0,012$ sehingga hipotesis nol ditolak, artinya ada hubungan dukungan sosial keluarga dengan pengendalian hipertensi di wilayah kerja Puskesmas Karangnunggal Tasikmalaya tahun 2018.

Hasil penelitian ini sejalan dengan penelitiannya Imran (2017) di Puskesmas Bantul bahwa dukungan keluarga berhubungan dengan kepatuhan pengendalian hipertensi. ${ }^{9}$ Keluarga memiliki peranan penting dalam proses pengawasan, pemeliharaan dan pencegahan terjadinya komplikasi di rumah. Selain itu keluarga dapat memberikan dukungan dan membuat keputusan mengenai perawatan yang dilakukan oleh penderita hipertensi (Tumenggung, 2013). ${ }^{11}$

Keluarga merupakan unit pelayanan karena masalah kesehatan keluarga saling berkaitan dan saling mempengaruhi antara sesama anggota sangat penting dalam tahap perawatan kesehatan, mulai dari tahap peningkatan kesehatan, pencegahan, pengobatan sampai dengan rehabilitasi.Dukungan keluarga bagi pasien hipertensi sangat dibutuhkan agar pasien merasa diperhatikan dan dihargai (Suparyanto, 2011).12

Sebagian besar dukungan sosial keluarga responden berada pada kategori baik $(70,4 \%)$. Dukungan sosial keluarga yang dimaksud adalah meliputi dukungan emosional, dukungan instrumental dan dukungan penghargaan. Dengan dukungan sosial dari keluarga yang baik, responden akan lebih baik dalam praktek pengendalian hipertensi.

2. Hubungan Pengetahuan dengan Perilaku Pengendalian Hipertensi

Tabel 13. Analisis Bivariat Hubungan Dukungan Sosial Keluarga dengan Perilaku Pengendalian Hipertensi di Wilayah Kerja Puskesmas Karangnunggal Tasikmalaya Tahun 2018

\begin{tabular}{|c|c|c|c|c|}
\hline \multirow[b]{2}{*}{ Pengetahuan } & \multicolumn{2}{|c|}{ Pengendalian Hipertensi } & \multirow{2}{*}{ Jumlah } & \multirow{3}{*}{$\begin{array}{l}\text { Nilai } \\
\qquad P\end{array}$} \\
\hline & Kurang Baik & Baik & & \\
\hline & $\begin{array}{c}\mathbf{f} \\
(\%)\end{array}$ & $\begin{array}{c}\mathbf{f} \\
(\%)\end{array}$ & $\begin{array}{l}f \\
\%\end{array}$ & \\
\hline \multirow[t]{2}{*}{ Kurang Baik } & 5 & 73 & 78 & \\
\hline & 6,4 & 93,6 & 100,0 & 0,03 \\
\hline \multirow[t]{2}{*}{ Baik } & 26 & 84 & 110 & \\
\hline & 23,6 & 76,4 & 100,0 & \\
\hline
\end{tabular}

Sumber : Data Primer, 2018 
Proporsi pengendalian hipertensi yang baik lebih banyak ditemukan pada responden yang memiliki pengetahuan baik $(76,4 \%)$ dibandingkan dengan pengendalian hipertensi yang kurang baik. Hasil analisis bivariat diperoleh nilai $p$ 0,03 sehingga hipotesis nol ditolak, artinya ada hubungan pengetahuan dengan pengendalian hipertensi di wilayah kerja Puskesmas Karangnunggal Tasikmalaya tahun 2018.

Hal ini sejalan dengan penelitiannya Utomo (2013) bahwa tingkat pengetahuan berhubungan dengan upaya pencegahan kekambuhan penderita hipertensi di Karanganyar dan penelitiannya Hapsari (2016). ${ }^{13}$ Menurut Notoatmodjo (2003) menjelaskan bahwa pembentukan perilaku individu dimulai dari adanya pengetahuan yang membentuk nilai yang diyakini dan sikap terhadap suatu hal. ${ }^{14}$ Pengetahuan dan sikap ini kemudian mengkristal dan secara sadar maupun tidak sadar akan membentuk perilaku atau tindakan. Tindakan yang berulang-ulang akan menjadi kebiasaan.

Jika pengetahuan responden tentang pengendalian hipertensi baik, maka hal ini akan berpengaruh pada bentuk praktek yang baik pula dalam perilaku pengendalian hipertensi. Hasil penelitian ini ditemukan sebagian besar responden memiliki pengetahuan tentang pengendalian hipertensi pada kategori kurang baik.Hal ini terjadi karena kurangnya informasi yang diperoleh responden mengenai bagaimana manajemen pasien hipertensi.Sedangkan dari sisi praktek pengendalian hipertensi, sebagian besar responden berada pada kategori
baik.Responden umumnya membatasi makanan cepat saji dan makanan kaleng, serta terbiasa untuk berjalan kaki dalam aktivitas sehari-hari.Seluruh responden juga rutin melakukan cek tekanan darah, yang dilakukan pada saat mengikuti klub Prolanis yang diadakan oleh Puskesmas Karangnunggal.Praktek pengendalian hipertensi yang kurang baik adalah masih rendahnya perilaku kepatuhan minum obat anti hipertensi dan hanya sebagian kecil responden yang sudah berhenti merokok.

Rendahnya kepatuhan minum obat pada responden dikarenakan sebagian besar responden tidak mengetahui bahwa obat hipertensi perlu diminum setiap hari meskipun tidak ada keluhan. Hal ini terbukti dengan sebagian besar responden kadang-kadang lupa untuk minum obat dan bahkan tidak minum obat saat tidak dirasakan adanya keluhan.Padahal kepatuhan minum obat adalah salah satu kunci penting dalam pengendalian hipertensi untuk mencegah komplikasi.Pihak puskesmas melalui kegiatan Prolanis perlu menekankan pentingnya patuh minum obat anti hipertensi pada pasien hipertensi.

\section{SIMPULAN DAN SARAN}

1. Simpulan

Faktor dukungan sosial keluarga dan pengetahuan berhubungan dengan praktek pengendalian hipertensi di Puskesmas Karangnunggal Kab. Tasikmalaya.

2. Saran

Agar Puskesmas Karangnunggal menekankan pentingnya pasien hipertensi untuk tidak lupa minum obat. 


\section{DAFTAR PUSTAKA}

1. Babatsikou F, Zavitsanou A. Epidemiology of hypertension in the elderly. Health Sci J. 2010;4(1):24-30

2. PERKI. PedomanTataLakasana Hipertensipada PenyakitKardiovaskular. 2015.

3. Balitbang Kemenkes RI. 2013.Riset Kesehatan Dasar; RISKESDAS. Jakarta.

4. PUSDATIN. 2015. Pusat Data dan Informasi Kementrian Kesehatan RI. Jakarta:Kemenkes,RI. [Online]

5. Dalyoko, Diah Ayu Pithalokka. Faktorfaktor yang Berhubungan dengan Upaya Pengendalian Hipertensi pada Lansia di Posyandu Lansia Wilayah KErja Puskesmas Mojongsono Boyolali. 2010 dalam http://eprints.ums.ac.id

6. Arif D, Rusnoto, Hartinah D. 2013.Faktor-faktor yang berhubungan dengan kejadian hipertensi pada lansia di pusling desa kumplit upt puskesmas gribig kabupaten kudus.JIKK. 4(2):1834.

7. Hadiyah DN, Setiawan. 2006. Analisis survival faktor-faktor yang mempengaruhi ketahanan hidup penderita hipertensi dengan terapi tablet captopril. [skripsi]. Surabaya: Institut Negeri Sepuluh Nopember.

8. Dewi TK. 2013. Gambaran pengetahuan warga tentang hipertensi di rw 02 sukarasa kecamatan sukasari. [skripsi]. Bandung: Universitas Pendidikan Indonesia.

9. Hairunisa, (2014). Hubungan Tingkat Kepatuhan Minum Obat Dan Diet Dengan Tekanan Darah Terkontrol Pada Penderita Hipertensi Lansia Di WilayahKerja Puskesmas Perumnas 1 Kecamatan Pontianak Barat. Skripsi.

10. Intan Siti Hulaima. Faktor-faktor yang Berhubungan dengan Kontrol Tekanan Darah pada Pasien Hipertensi di PUskesmas Kedaton Kota Bandar Lampung. 2017.[Skripsi] dalam http:/www.diglib.unila.ac.id pada tanggal 10 februari 2018

11. Imran, Ali (2017). Hubungan Dukungan Keluarga dengan Kepatuhan Pengendalian Hipertensi pada Lansia di Puskesmas Pandak Bantul Yogjakarta.[Skripsi]. STIKes Jendral Ahmad Yani. Yogjakarta.

12. Hapsari, Dea Prastika (2016). Hubungan Pengetahuan dengan Perilaku Manajemen Hipertensi : Aktifitas Fisik dan Diet DASH Penderita Hipertensi di Desa Salamrejo Yogyakarta. [Skripsi] diakses dalam http://repository.umy.ac.id pada tanggal 9 September 2018.

13. Notoatmodjo, Soekidjo (2003). Pendidikan dan Perilaku Kesehatan. Rineka Cipta. Jakarta 
